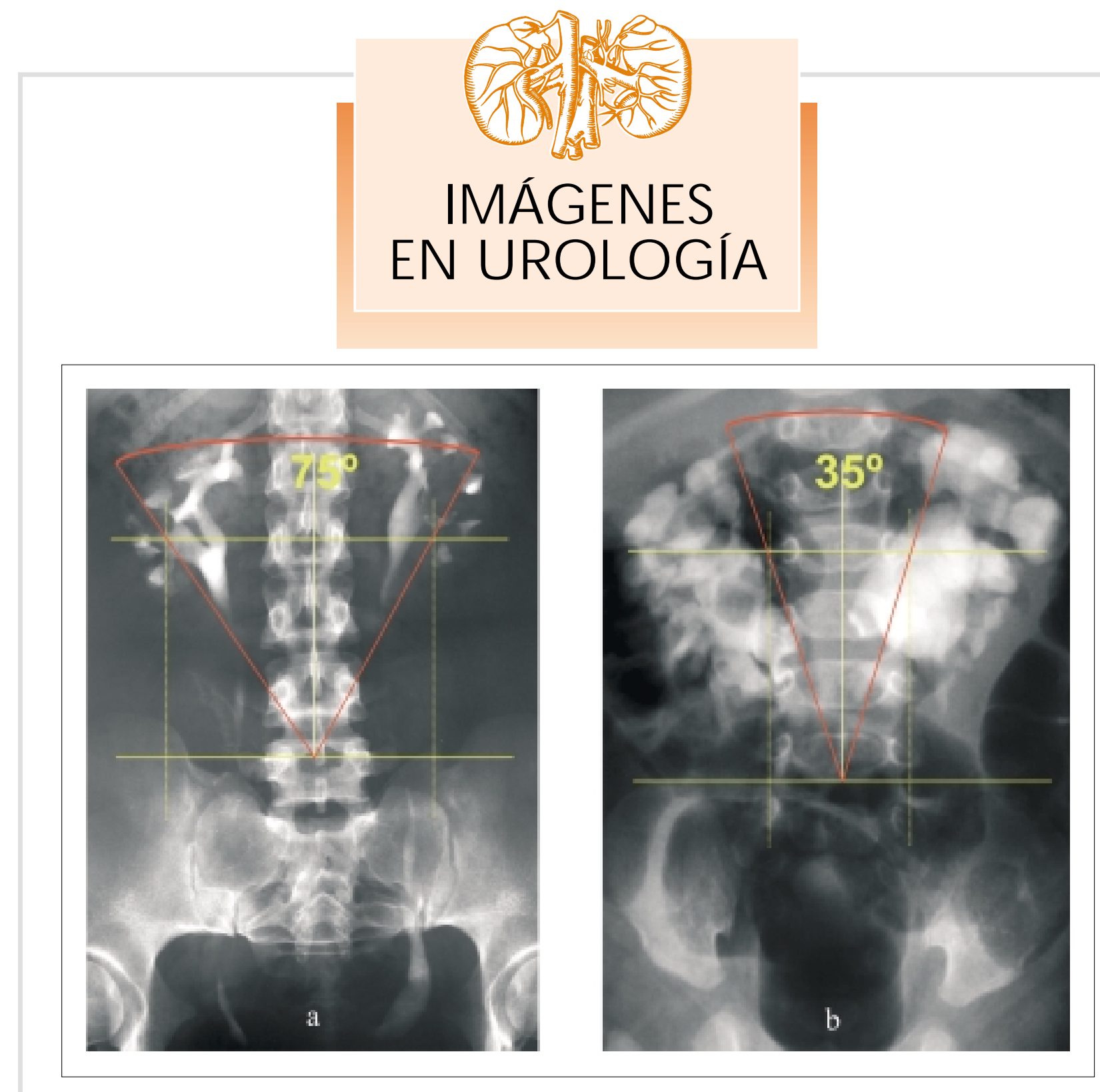

\title{
ÁNGULO DE GUTIÉRREZ
}

El urólogo cubano R. Gutiérrez publicó en el año 1931 y posteriormente en 1934 sendos trabajos sobre el manejo del riñón en herradura, describiendo el signo radiológico que lleva su nombre de la siguiente manera:

"Se traza una linea horizontal que una el borde superior de las dos crestas iliacas; paralelas a ésta, una segunda linea cruza la columna vertebral a nivel de la segunda vértebra lumbar. En el extremo más interno de la imagen del cáliz inferior de cada lado se traza una vertical paralela a la columna vertebral. El cruce de esta linea con la horizontal superior marca la base de un triángulo, cuyo vértice corresponde al cruce de la horizontal inferior con la linea espinal. Estos tres puntos señalan un triángulo cuyo ángulo inferior normalmente oscila entre 64 y 103(a). Por el contrario, en el riñón en herradura, la abertura del ángulo inferior oscila entre 7 y 37(b). Este signo deja de cumplirse excepcionalmente".

\section{REFERENCIAS}

1. Garat JM. Malformaciones del aparato urogenital en: Urología Pediátrica. JM Garat y R Gosálbez ed. Salvat. Barcelona 1987.

2. Gutiérrez R. The clinical management of horseshoe kidney. Am J Surg 1931;14:657-688.

3. Gutiérrez R. The clinical management of horseshoe kidney. Ed. P.B. Hoeber. N. Yor, 1934

4. Zungri E, et al. Riñón en herradura. Act Fund Puigvert. 1979;9(1):41-51. 